\title{
Influence of Residents' Perception of Tourism's Impact on Supporting Tourism Development in a GIAHS Site: The Mediating Role of Perceived Justice and Community Identity
}

\author{
Bojie Wang ${ }^{1,2}\left(\mathbb{D}\right.$, Siyuan $\mathrm{He}^{1, *(\mathbb{C})}$, Qingwen Min ${ }^{1,2} \mathbb{( D}$, Feng Cui ${ }^{3}$ and Guoping Wang ${ }^{1,2}$ \\ 1 Institute of Geographic Sciences and Natural Resources Research, Chinese Academy of Sciences, \\ Beijing 100101, China; wangbj.19b@igsnrr.ac.cn (B.W.); minqw@igsnrr.ac.cn (Q.M.); \\ wanggp.18b@igsnrr.ac.cn (G.W.) \\ 2 College of Resources and Environment, University of Chinese Academy of Sciences, Beijing 100049, China \\ 3 College of Humanities \& Social Development, Nanjing Agricultural University, Nanjing 210095, China; \\ cuifeng@njau.edu.cn \\ * Correspondence: hesy@igsnrr.ac.cn; Tel.: +86-10-6488-9810
}

\section{check for} updates

Citation: Wang, B.; He, S.; Min, Q.; Cui, F.; Wang, G. Influence of Residents' Perception of Tourism's Impact on Supporting Tourism Development in a GIAHS Site: The Mediating Role of Perceived Justice and Community Identity. Land 2021, 10, 998. https://doi.org/10.3390/ land10100998

Academic Editor: Alastair M. Morrison

Received: 23 August 2021 Accepted: 20 September 2021 Published: 22 September 2021

Publisher's Note: MDPI stays neutral with regard to jurisdictional claims in published maps and institutional affiliations.

Copyright: (C) 2021 by the authors Licensee MDPI, Basel, Switzerland. This article is an open access article distributed under the terms and conditions of the Creative Commons Attribution (CC BY) license (https:// creativecommons.org/licenses/by/ $4.0 /)$.

\begin{abstract}
How we scientifically measure residents' perception of tourism developments and earn their understanding and support have an important impact on the scientific management and sustainable utilization of tourist attractions. This study analyzes the mediating role of perceived justice and community identity between residents' perceptions of tourism's impact and their support for tourism development by integrating the theories of social exchange theory (SET) and 'cognitionaffection-conation' (CAC) relationship theory. We surveyed 334 interviewees in the Xinghua Duotian Agrosystem (XHDA), a Globally Important Agricultural Heritage Systems (GIAHS) site in Jiangsu Province, China. The findings of our study are as follows: (1) Residents' perceptions had both a direct and indirect influence over behavioral intentions. Specifically, benefit perception of tourism had a significant positive influence, while cost perception had a significant negative influence on residents' support for tourism development. (2) Perceived justice and community identity played an intermediary role in the relationship between tourism impact perception and support for tourism development. (3) The mediating role of emotions had strong effects on their behavioral intentions via its psychological transmission chain of perceptions. The results suggest that community-based tourism (CBT) may be an effective tool for local residents to diversify their livelihoods in the GIAHS site, and the mediating role of perceived justice and community identity should be taken seriously for the development of CBT in GIAHS sites.
\end{abstract}

Keywords: globally important agricultural heritage systems (GIAHS); community-based tourism (CBT); tourism's influence; community development; sustainable livelihoods; perceived justice; community identity; Xinghua Duotian Agrosystem (XHDA)

\section{Introduction}

Tourism is widely considered an effective contributor to poverty reduction and economic development for some traditional communities around the world [1]. Tourism and hospitality create diversified employment opportunities in different sectors, acting as a catalyst for the transition from traditional ways of life to so-called modern forms of society; however, the introduction of new behavior trends and norms can come into conflict with the cultural identity of the host community and threaten the traditional value systems there [2]. Responding to criticism of tourism development as lacking awareness of cultural understanding, social justice, and ecological degradation, community-based tourism (CBT) has been introduced and widely identified for its ability to promote the harmonious relationships between visitors and the local community on the premise that tourism should address the fundamental needs and concerns of the local community [3]. 
Community residents are one of the core stakeholders in tourist destinations because they are the main participants in tourism and are largely influenced by tourism activities. Thus, their perceptions of tourism development are crucial to initiating and maintaining CBT through active participation and to deliver economic, environmental, and socio-cultural outcomes of sustainable tourism.

Some studies have attempted to apply the principles of social exchange theory (SET) to explain the reactions of residents to tourism in the community since the 1970s [4]. This theory assumes that individuals select exchanges after having assessed rewards and costs [5]. Most studies have conceptualized the social exchange between the tourism industry and residents in various ways by using multiple variables. For example, Ap used the logic of SET to explore the relationship between residents' perceptions of their power to control tourism and their support for tourism development [6]. Jurowski further explored how the interplay of exchange factors influences not only the attitude regarding tourism but also the host community residents' perceptions of tourism's impacts [7]. Many studies confirmed that the positive and negative impacts of tourism were direct influential factors for local residents to react to tourism development [8]. The perceptions of various economic, socio-cultural, and environmental impacts are found to be related strongly to tourism development, and these impacts indicate local residents' willingness to enter into an exchange relationship with the tourism industry [9]. Yet, SET as a holistic framework may lead to conflicting conclusions [5]. For example, some researchers found that some variables of tourism's impacts can predict personal benefits and residents' reactions to tourism development [10], while others found no such relationships [11,12]. Some researchers attributed the conflicting discoveries to the lack of mediating variables in the SET-based framework, in which residents' cognition, i.e., their positive and negative attitudes towards tourism's impacts, directly led to their behavior, i.e., residents' support for tourism development or not. Thereafter, many factors, such as the personal benefits, the level of trust, and the distribution of power between stakeholders were found to play important roles in explaining local residents' support for tourism development [10,13,14]. Accordingly, the 'cognition-affection-conation' (CAC) relationship theory was believed to be effective in explaining human behaviors with the influence of psychological factors [15]. For example, Li and Yang pointed out that efficiency and equity are important mediating factors [16]. Shan identified the community's cultural identity as a mediating factor for residents' support for tourism development [17]. Guo identified that quality of life and community attachment were important factors regarding residents' perceptions of tourism's impact and their support for tourism development [18]. Therefore, CAC theory can make up for the lack of consideration of mediating factors in SET to explore the relationship between the local community and tourism development.

Since the concept of CBT links visitation to natural areas with local well-being to meet ecological conservation goals, many studies of community development have been conducted in various protected areas and heritage sites where tourism is usually taken as an effective tool to balance conservation and development [19]. One type of tourist destination is gaining growing attention concerning the role of local communities in conservation. Globally Important Agricultural Heritage Systems (GIAHS) are developed through humannature interactions over a long period. As well-developed agricultural systems, they contribute greatly to food production, livelihood security, and social stability for local communities [20]. However, in many rural communities, the traditional systems with abundant biodiversity, cultural and landscape values are degrading, partly due to the low income associated with agriculture [21]. As a living heritage, local residents are the creators and keepers of the system, and so the conservation of GIAHS greatly depends on local residents' decision making regarding their livelihoods [22]. CBT is supposed to be an effective tool for local residents to diversify their livelihoods by sustaining the traditional systems through added value, and thus it is also an important strategy for the dynamic conservation and adaptive management of GIAHS [23]. CBT in GIAHS is special because local communities, the residents, and their agricultural activities are tourist attractions 
themselves. Therefore, the investment of external capital and administrative forces must operate in GIAHS based on the understanding of the traditional system in terms of land use and resource management as well as the local socio-cultural context [24]. In addition, host communities in GIAHS participate deeply and fairly in tourism development to conserve the system [25]. The involvement of external capital will affect the benefit distribution of CBT, and residents' support for tourism development [3]. However, few studies have been performed to identify both the direct and indirect factors that can affect local residents' behaviors in this process in GIAHS. Previous studies have noted that residents' perceptions of justice and community identity are crucial in mediating their support for tourism development [26], but the mechanism of this psychological process is still not entirely clear.

Thus, through the case of a GIAHS site, Xinghua Duotian Agrosystem (XHDA) in eastern China, we aim to explore the direct relationship between the impacts of tourism and residents' support for tourism, with perceived justice and community identity as mediating variables based on the analytical framework constructed under the principle of SET and CAC. In social science research, the intermediary effect (IE) is an important indicator to measure the relationship between the intermediary, independent, and dependent variable in the causal chain, in which complete mediation (CM) means that the intermediary effect exists completely and partial mediation (PM) means that there are both direct and mediation effects [27]. By measuring IE, the impact of psychological factors on residents' support for tourism development can be quantified.

The research objectives are threefold: (1) identifying the relationship between residents ${ }^{\prime}$ perception of tourism's impact and support for tourism development; (2) assessing the influences of perceived justice and community identity on the perception and behaviors of residents, especially the CM and PM effects; and (3) broadening the understanding of SET and CAC, as well as helping GIAHS communities to determine the development opportunities and strategies for CBT.

\section{Literature Review and Hypotheses}

\subsection{The Foundations of the Research}

Studies into residents' perceptions can be traced back more than forty years. In the early years, several well-known models were developed to detect the relationship between residents' perceptions of tourism's impact and tourism development. In particular, the 'irridex' model [28], social exchange theory [5], tourist typology theory [29], and seminal resort life-cycle theory [30] all identified that residents showed growing negative perceptions towards the development of tourism, i.e., perceptions of tourism became more negative as the sector became more developed/mature [31]. However, these models were criticized for their inherent linearity and assumptions, i.e., assuming that residents perceptions were only related to material factors, whilst ignoring the socio-cultural context and psychology of individuals. Accordingly, the predicted results were often inconsistent with the practice of tourist destinations. Gradually, the research focus returned from extrinsic variables to the residents themselves to adopt a 'tourism perception' approach. Multiple methods, including social investigation and complex statistical methods such as factor analysis, cluster analysis, regression analysis, structural equation modeling, etc., have been widely used to measure residents' perceptions. As McGhee and Anderek argued, 'understanding residents' perceptions on the impacts of tourism is even more important than understanding the impacts of tourism itself' [32].

The term 'perception' is widely used by researchers [33], while at the same time, 'attitude' [34] or 'opinion' [35] are also often used. 'Perception' is the basis and premise of 'attitude', which is more concerned with psychological variables that affect the formation of behaviors. 'Attitude' is based on a series of perceptions of the tourism industry and its impacts in different aspects, and is usually expressed as positive or negative. 'Opinion' is the view of residents towards the results caused by tourism development, which is unique and different to each individual, while 'perception' represents the overall opinion 
of the group. Because this study aims to understand the mediating variables of community residents' support for tourism, we use 'perception' to express this term in this study.

To address the research objectives of this study, we developed a theoretical framework (Figure 1) based on SET [5] and CAC [15] to address residents' perception of tourism's impact and its effect on them supporting tourism development, with perceived justice and community identity as mediating variables. Based on the above statements, the following research hypotheses are proposed.

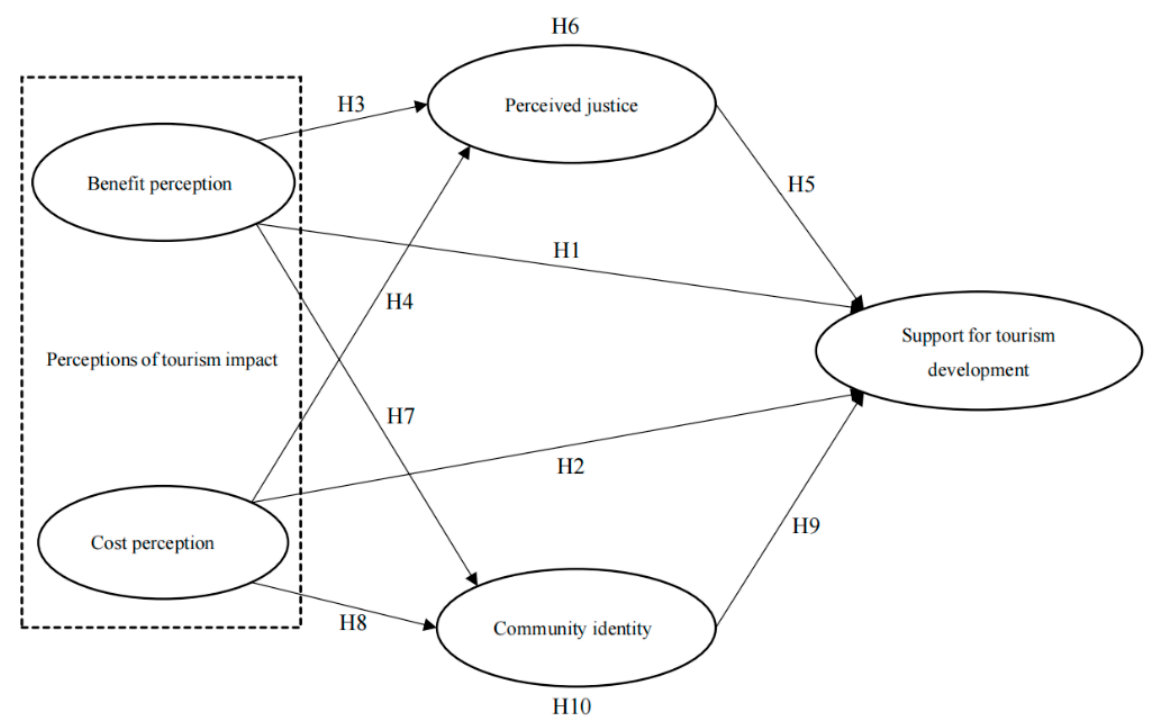

Figure 1. A theoretical framework based on SET and CAC.

\subsection{Resident's Perceptions of Benefits and Cost Impacts}

Previous research on the impacts of tourism has reached a consensus that residents feel that tourism brings both benefits and costs to their community concerning economic, socio-cultural, and environmental outcomes [8]. The economic dimension has been found to be the most important aspect of residents' perceptions. Research confirms that tourism can increase economic income and enhance human welfare through employment opportunities [36] as well as improvements to community facilities and public infrastructures [37]. Nevertheless, residents are aware that tourism increases the cost of living, widens the income gap, and leads to inflation in the tourist destination [38].

As for the socio-cultural dimension, tourism affects the characteristics of the community and its residents, such as customs, beliefs, habits, and values. Interactions between community residents and tourists stimulate cultural communication, enhancing residents' pride and cultural identity [39]. However, residents also perceive some negative impacts, such as traffic congestion and parking problems in the community. Residents even sometimes notice increases in theft, robbery, and other serious crimes [40].

Tourism activities are often developed in areas with attractive resources but a relatively fragile environment, which is a challenge for resource conservation. Research shows that community residents identify the environmental impacts of tourism development. Tourism helps to preserve natural and cultural resources and improves the environment of the community, but it causes air, water, and soil pollution [41].

Since the impacts of tourism concerning benefits and cost are significantly perceived by residents, we cannot ignore their role in supporting tourism development. Thus, it is hypothesized that:

Hypothesis 1 (H1). Tourism benefit perception has a significant positive influence on supporting tourism development.

Hypothesis 2 (H2). Tourism cost perception has a significant negative influence on supporting tourism development. 


\subsection{Perceived Justice}

The participation of residents is the basis, premise, and primary approach for the sustainable development of tourist destinations, and it is also the specific embodiment of justice in CBT. The justice theory (TJT) [42] has been adopted as a powerful vehicle for explaining the relationship between organizations and individuals [43]. A sense of justice refers to the subjective psychological perception among the members of an organization of the justice of policies, systems, and measures related to personal interests and consists of three main forms, namely distributive, procedural, and interactional justice [44].

According to TJT, distributive justice refers to 'the allocation of costs and benefits in achieving equitable exchange relationships' [45], which primarily concerns the outcomes provided to local residents from the development of CBT. Local residents not only pay attention to their gains and losses but also compare them with those of others. Procedural justice refers to 'the perception of justice concerning rules and procedures of decisionmaking on the distribution of benefit' [46] and it occurs in several stages of decisionmaking and distribution processes required for the development of CBT. Interactional justice reflects the evaluation of the degree to which residents have experienced justice in interpersonal interactions with the decision-makers during the enactment of procedures. Decision-makers should explain and share information on CBT development activities with residents in an equal and respectful manner to enhance the sense of interaction and equity.

As for CBT, Murphy pointed out that positive justice can improve residents' perceptions of tourism development and better guides residents to integrate into tourism planning [47]. However, negative justice will lead to resistance from residents and urges them to reject the development of tourism in the community. Wahab and Pigram also believed that only by paying attention to the equitable sharing of outcomes from tourism development among community residents can CBT at the community level be successfully achieved [48].

Therefore, it is assumed that the participation of residents in planning and decisionmaking can effectively reduce conflicts with other stakeholders in tourism development. Residents' perception of justice is an important variable to determine the participation of communities in CBT.

Thus, it is hypothesized that:

Hypothesis 3 (H3). Tourism benefit perception has a significant positive impact on perceived justice.

Hypothesis 4 (H4). Tourism cost perception has a significant negative impact on perceived justice.

Hypothesis 5 (H5). Perceived justice has a significant positive impact on supporting tourism development.

Hypothesis 6 (H6). Perceived justice plays an intermediary role in the relationship between tourism impact perception and support for tourism development.

\subsection{Community Identity}

Community identity refers to the extent to which residents feel that they are in accord with the group characteristics from interactions [49] and is the extent to which residents feel an emotional connection as community members. Community identity is dynamically responsive to changes in age, social class, personality, and other individual characteristics [50] and the sense of gain and loss after changes to the social environment. For example, De Bres and Davis demonstrated that community identity plays a positive role in promoting festival tourism development, and it also enhanced the cohesion of the community and the inheritance of festival culture [51]. Carrus found that an industry with significant negative impacts harmed people's identity [52]. 
In terms of CBT, the perception of benefits brought about by tourism development will enhance residents' sense of identity and loyalty to the community and then their support for tourism development. On the contrary, if the perception of cost brought about by tourism development is strong, some community residents with high loyalty will show strong rejection and resistance towards CBT out of the sense of responsibility to protect the community, and these community representatives will affect other community members to form a collective resistance to tourism development.

Thus, it is hypothesized that:

Hypothesis 7 (H7). Tourism benefit perception has a significant positive impact on community identity.

Hypothesis 8 (H8). Tourism cost perception has a significant negative impact on community identity.

Hypothesis 9 (H9). Community identity has a significant positive impact on supporting tourism development.

Hypothesis 10 (H10). Community identity plays an intermediary role in the relationship between tourism impact perception and support for tourism development.

\section{Materials and Methods}

\subsection{Study Area}

This study took Xinghua Duotian Agrosystem (XHDA) as the research base. XHDA $\left(32^{\circ} 56^{\prime} \sim 33^{\circ} 07^{\prime} \mathrm{N}, 119^{\circ} 43^{\prime} \sim 119^{\circ} 55^{\prime} \mathrm{E}\right)$ is located in the northwest of Xinghua City, Jiangsu Province. It was recognized as a GIAHS site in 2014 by the Food and Agriculture Organization of the United Nations (FAO) and covers 5 townships, including the towns of Duotian, Ganggu, Zhoufen, Lizhong, and Xijiao, with an area of $312 \mathrm{~km}^{2}$ (Figure 2). The GIAHS site has a history dating back about 600 years. To reduce flood risk, farmers dug up and stacked the sludge in the marshland to form ridges where they can plant crops, vegetables, etc. (Figure 3). Thus, FAO stated that 'Xinghua Duotian Agrosystem is a world-level wonder for its unique water-land utilization method in low-lying land and its splendid raised field landscape' [53].

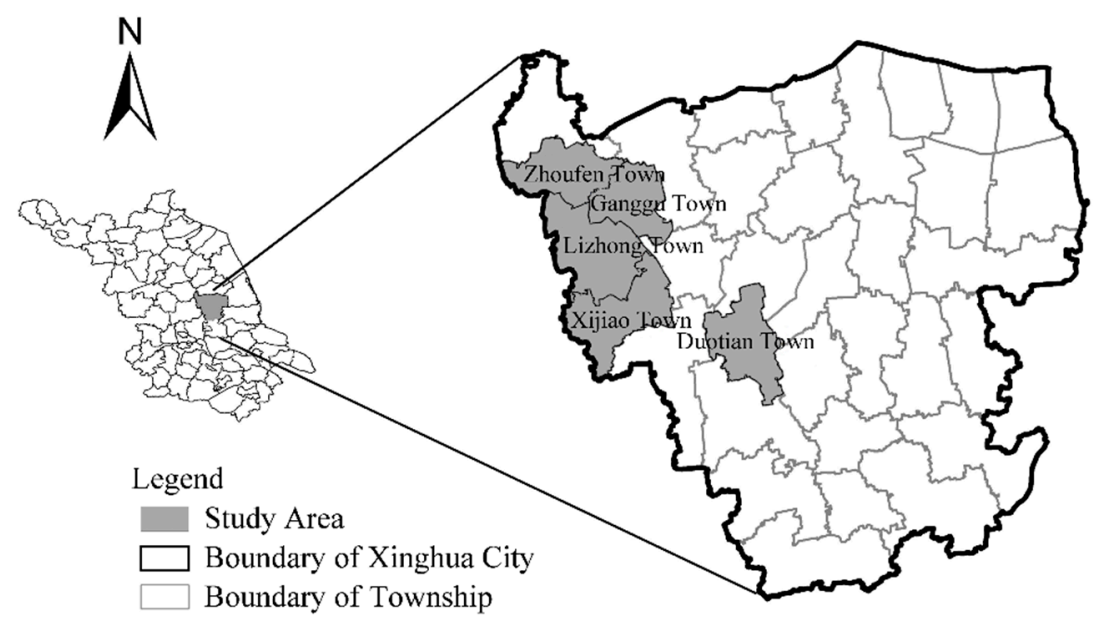

Figure 2. Location and range of Xinghua Duotian Agrosystem. 

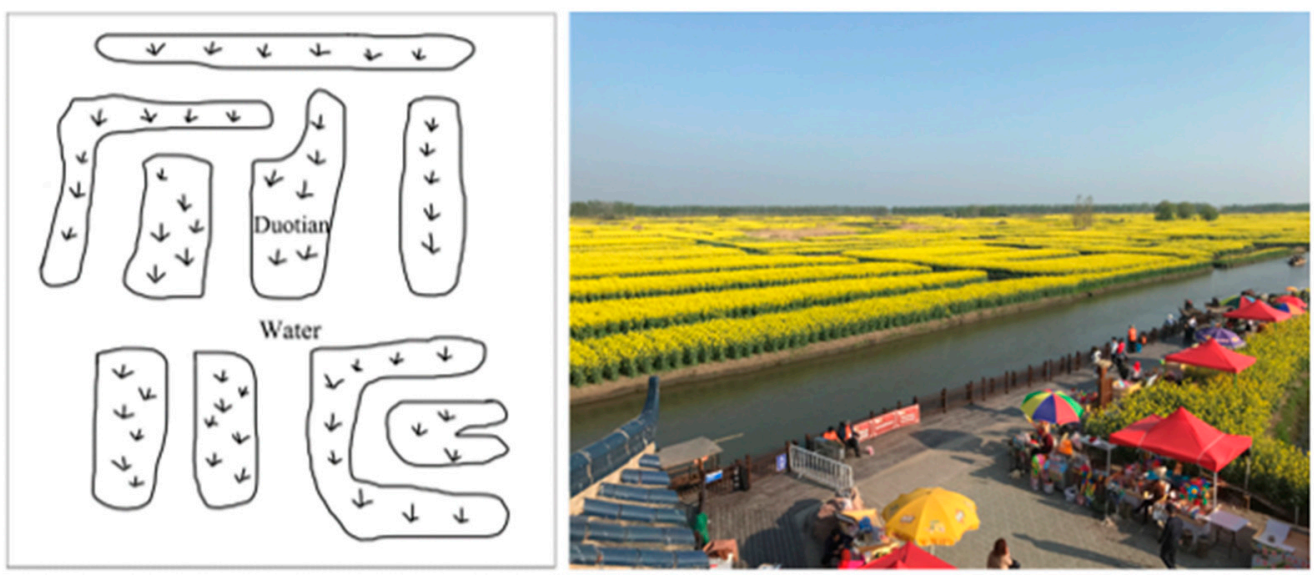

Figure 3. The sketch map and agri-landscape of Xinghua Duotian Agrosystem.

In this unique agri-landscape, the raised fields and the surrounding water offers opportunities for production with traditional methods to form a three-dimensional system composed of agriculture, forestry, and aquaculture. The natural environment, magnificent agri-landscape, and rich folk culture in XHDA are the fundamental elements of GIAHS, and CBT is regarded as an effective tool for the conservation and management of this precious heritage. Local community residents in XHDA are widely involved in tourism as a way of livelihood. In 2018, XHDA received 2.42 million tourists, with a total tourism income of about CNY 1.82 billion (ca. 28.08 million dollars) (https:/ / data.stats.gov.cn/, accessed on 10 August 2021). As the core stakeholders of this agri-landscape, local residents are deeply affected by CBT regarding their lifestyle and quality of life [22]. In this process, residents have deeply participated in tourism-related catering, accommodation, transportation, entertainment, etc.

\subsection{Measurement Development}

The construct measurements and questionnaire were adopted from previous studies. The questionnaire included four parts: the first part contained the socio-demographic information of the interviewee, such as gender, age, education level, residence time, and income level. The second part detailed the local resident's perception of the impacts of tourism, including benefit perception and cost perception. The third part detailed the resident's perceived justice (including the three dimensions of TJT: distributive, procedural, and interactional justice) and community identity. The last part comprised the degree of local resident's support for tourism development.

To ensure the reliability and validity of the variable measurement, this paper adopted mature scales from previous studies [54-56] and modified them according to the actual situation of the GIAHS site. Before the formal survey, a pretest of the questionnaire was conducted. First, three professors of tourism management, human geography, and natural conservation were invited to evaluate the measurement scales in terms of their wording and easiness-to-understand. Comments and suggestions were considered to reach a final version of the scale (Table 1). All of the observed variables were measured with a 5-point Likert scale, with an evaluation value of 5 to 1 from strongly agree to strongly disagree, respectively. To check the reliability of this scale, a pretest was then conducted with 20 undergraduate students from a university in southern China. The result of the pretest suggested that all of the values of Cronbach's alpha coefficients were larger than the threshold point of 0.7 , indicating the statistical reliability of the proposed measurement scale. 
Table 1. Measurement variables and questionnaire design.

\begin{tabular}{|c|c|}
\hline Measurement Variables & Questions \\
\hline \multirow{6}{*}{ Benefit perception } & Tourism provides more job opportunities for the community (A1) \\
\hline & Tourism improves the infrastructure of the community (A2) \\
\hline & Tourism promotes the cultural exchange between residents and tourists (A3) \\
\hline & Tourism promotes the conservation of GIAHS (A4) \\
\hline & Tourism promotes the economic development of the local community (A5) \\
\hline & I can get a certain dividend from the tourism development income of GIAHS (A6) \\
\hline \multirow{5}{*}{ Cost perception } & Tourism destroys the natural environment of the community (B1) \\
\hline & Tourism leads to an inflation of the community (B2) \\
\hline & Tourism makes the local traffic more congested (B3) \\
\hline & Tourism erodes the local traditional culture (B4) \\
\hline & Tourism aggravates the income gap among residents in the community (B5) \\
\hline \multirow{8}{*}{ Perceived justice } & The result of distribution can reflect the labor I paid for CBT $(\mathrm{C} 1)$ \\
\hline & The income gap between residents is reasonable $(\mathrm{C} 2)$ \\
\hline & I am satisfied with the distribution results of CBT (C3) \\
\hline & There are certain rules and regulations in the distribution process $(\mathrm{C} 4)$ \\
\hline & There is no bias in the distribution process (C5) \\
\hline & My opinions and suggestions can be considered in the distribution process (C6) \\
\hline & The relationship between the GIAHS managers and me is harmonious (C7) \\
\hline & The GIAHS managers are polite and respectful to me (C8) \\
\hline \multirow{5}{*}{ Community identity } & I feel proud as a member of the GIAHS site and community (D1) \\
\hline & The development of tourism in Duotian is relevant to me (D2) \\
\hline & I think it is my responsibility to protect Duotian (D3) \\
\hline & I will feel sad if leaving the community (D4) \\
\hline & I will feel proud when others praise Duotian (D5) \\
\hline \multirow{6}{*}{$\begin{array}{l}\text { Support for tourism } \\
\text { development }\end{array}$} & I support the community to carry out in-depth CBT (E1) \\
\hline & I support the community to increase investment in CBT (E2) \\
\hline & I welcome more tourists (E3) \\
\hline & I am willing to participate in CBT of tourism planning and decision-making of Duotian (E4) \\
\hline & I am willing to participate in the daily management of Duotian (E5) \\
\hline & I am willing to maintain the tourism image of Duotian (E6) \\
\hline
\end{tabular}

\subsection{Survey}

As of 2020, XHDA contained 24 villages with approximately 1020 households that were engaged directly or indirectly in GIAHS-related activities. The income from such activities could account for up to $90 \%$ or more of the village's total economic income. About $70 \%$ of these residents were engaged in CBT-related business, which has become an important source of their income. Thus, the livelihood of the local residents was closely linked to the CBT of XHDA. Household interviews were conducted in five villages of Dongwang, Xiwang, Xiluo, Heigao, and Zhuye village. These villages are the closest to the core conservation area of XHDA with a growing development of CBT, and there is little difference in livelihood strategies for the residents. Local residents have lived on the Duotian for generations, making them representative for this study. The sampling units in this study were individuals who reside in these villages. To better communicate with the interviewees, five undergraduate students who were familiar with the local dialect were trained to help communicate with interviewees. A random sampling method was used along each street in these five villages considering the overall number of households and their socio-economic homogeneity.

Before the questionnaire was issued, the interviewees were asked to confirm whether they were local permanent residents (not immigrants) living in the core area of the GIAHS site. The survey was conducted in three periods of 3-17 March, 24-28 April, and 17-21 July in 2017. Since the peak seasons of tourism are March and April, surveys in multiple months can balance out the interference of seasonality in the data. A total of 368 questionnaires were distributed, of which 334 were valid, with an effective rate of $90.7 \%$. 


\subsection{Model and Data Analysis}

Structural equation modeling (SEM) is a statistical method to express the relationship between observed variables and latent variables to test distinct mechanisms through a linear equation system [57]. For this study, residents' perceptions (latent variables) at the psychological level cannot be directly and accurately measured and so the relationship between their perceptions and support for tourism is different to attain. SEM can effectively solve this problem by introducing measurable observation variables for latent variables [58]. Through a structured scale, residents' mental activity processes can be explicitly expressed [59]. With statistical analysis of observation variables in scale, the purpose of studying latent variables is realized.

The SEM consists of three matrix equations:

$$
x=\Lambda_{x} \xi+\delta
$$

where $x$ represents the exogenous observation variables, $\xi$ represents the exogenous latent variables, $\Lambda_{x}$ represents the factor load matrix of exogenous observed variables on exogenous latent variables, and $\delta$ represents the error term of the exogenous latent variables.

$$
y=\Lambda_{y} \eta+\varepsilon
$$

where $y$ represents the endogenous observation variables, $\eta$ represents the endogenous latent variables, $\Lambda_{y}$ represents the factor load matrix of endogenous observed variables on endogenous latent variables, and $\varepsilon$ represents the error term of the endogenous latent variable.

$$
\eta=B \eta+\Gamma \xi+\zeta
$$

where $\eta$ represents the result of SEM, $B$ and $\Gamma$ are path coefficients with $B$ representing the relationship among endogenous latent variables and $\Gamma$ representing the influence of exogenous latent variables on endogenous latent variables, and $\xi$ represents the error term of SEM.

Equations (1) and (2) are measurement models, and Equation (3) is the structural equation model.

To test the mediating effect, the commonly used methods include the causality method, Sobel test, and bootstrap method. The statistical effect of the causal method is usually lower than the bootstrap method. The Sobel test needs to assume that the samples are normally distributed with indirect effects, but they often show the non-normal distribution in practice [60]. Thus, the bootstrap method was used to test the mediating effect in this study.

SPSS 18.0 was used to test the reliability of the collected data and the consistency within the scale. The model fitting degree and the assumed path coefficient were analyzed and tested by AMOS 20.0.

\section{Results}

\subsection{Demographic Structures of Interviewees}

Table 2 presents the interviewees' demographic profiles. Approximately $80 \%$ of the interviewees had resided in the heritage site for at least 10 years. The samples had a balanced ratio of males and females, and more than $75.4 \%$ of the interviewees were between 19 and 45 years of age. Education levels of junior high school and primary school and below were the most common, accounting for $43.2 \%$ and $19.9 \%$ of the sample, respectively. The annual income of most households was between 8500 and 13,500 dollars, which was about three times the local per capita income in 2017 (http:/ /www.taizhou.gov.cn/, accessed on 10 August 2021), and the main sources of family income were directly and indirectly associated with agri-landscape, i.e., accommodation and catering of CBT. 
Table 2. The demographic characteristics of the research samples.

\begin{tabular}{|c|c|c|c|}
\hline Items & Classification & Frequency & Percentage $(\%)$ \\
\hline \multirow{2}{*}{ Gender } & Male & 169 & 50.6 \\
\hline & Female & 165 & 49.4 \\
\hline \multirow{5}{*}{ Age } & Under 19 & 3 & 0.9 \\
\hline & 19-30 years old & 84 & 25.1 \\
\hline & $31-45$ years old & 168 & 50.3 \\
\hline & 46-60 years old & 74 & 22.2 \\
\hline & Over 61 years old & 5 & 1.5 \\
\hline \multirow{5}{*}{ Education degree } & Primary school and below & 52 & 15.6 \\
\hline & Junior high school & 144 & 43.2 \\
\hline & High school/technical school & 66 & 19.9 \\
\hline & Undergraduate/Associate's degree & 70 & 21.0 \\
\hline & Postgraduate degree & 2 & 0.3 \\
\hline \multirow{4}{*}{ Residence time } & Less than 5 years & 23 & 7.0 \\
\hline & 6-10 years & 41 & 12.2 \\
\hline & $11-20$ years & 68 & 20.3 \\
\hline & 20 years and above & 202 & 60.5 \\
\hline \multirow{5}{*}{ Total annual income of household } & Less than 6000 dollars & 55 & 16.6 \\
\hline & 6000-8500 dollars & 157 & 46.9 \\
\hline & $8500-11,000$ dollars & 68 & 20.3 \\
\hline & 11,000-13,500 dollars & 38 & 11.4 \\
\hline & More than 13,500 dollars & 16 & 4.8 \\
\hline \multirow{8}{*}{$\begin{array}{l}\text { The main source of family income } \\
\text { (The main source: the source of } \\
\text { income that accounts for more than } \\
60 \% \text { of the total income.) }\end{array}$} & Tourist shop & 5 & 1.0 \\
\hline & Homestay & 24 & 7.1 \\
\hline & Passenger or freight transportation & 8 & 2.9 \\
\hline & Planting or breeding & 83 & 24.9 \\
\hline & Handicraft & 42 & 12.6 \\
\hline & Logistic service of GIAHS site & 87 & 26.0 \\
\hline & Migrant work & 78 & 23.4 \\
\hline & Others & 7 & 2.1 \\
\hline
\end{tabular}

\subsection{Data Reliability and Validity Test}

Reliability refers to the consistency of the results obtained when the same variables are used for repeated measurements of the questionnaire. In the reliability test, the higher is the reliability coefficient, the more reliable is the questionnaire. It is generally believed that a reliability coefficient that is greater than 0.75 indicates good reliability, and a reliability coefficient that is lower than 0.4 indicates poor reliability [61]. The results show that the alpha $(\alpha)$ coefficients of the five latent variables were between 0.844 and 0.924 , which indicated that the internal reliability of the questionnaire was high.

The Kaiser-Meyer-Olkin (KMO) test is used to test the feasibility of the collected data for factor analysis, and it is one of the validity indexes of principal component analysis. It is commonly believed that a KMO value of 0.9 or more means that the data are very suitable for factor analysis, $0.8-0.9$ means they are suitable, $0.7-0.8$ means they are neutral with regards to suitability, $0.6-0.7$ means they are not suitable, and below 0.5 means they are extremely unsuitable [62]. The results show that the overall $\mathrm{KMO}$ value of the questionnaire was 0.912 , and the Bartlett test showed that the variables were significantly correlated at the significance level of 0.000 , indicating that the questionnaire was suitable for factor analysis.

\subsection{Confirmatory Factors Analysis}

Table 3 shows the fitting degree of the confirmatory factor analysis, including contrast media-induced nephropathy $(\mathrm{CMIN} / \mathrm{DF}=1.446)$, standardized root mean square residual $(\mathrm{SRMR}=0.06)$, root mean square error of approximation (RMSEA $=0.037)$, and incremental and absolute model fit indices (e.g., GFI $=0.906$, AGFI $=0.884$, and CFI $=0.974$ ). All the fitting indices were examined and were within the acceptable range of adequate fit [63]. Therefore, the model had good fitness. 
Table 3. The fitting degree of confirmatory factor analysis.

\begin{tabular}{ccccccc}
\hline $\begin{array}{c}\text { Fitting } \\
\text { Degree }\end{array}$ & CMIN/DF & SRMR & RMSEA & GFI & AGFI & CFI \\
\hline Standard & $<3$ & $<0.08$ & $<0.08$ & $>0.9$ & $>0.8$ & $>0.9$ \\
Result & 1.446 & 0.06 & 0.037 & 0.906 & 0.884 & 0.974 \\
Conclusion & Pass & Pass & Pass & Accept & Pass & Pass \\
\hline
\end{tabular}

Note: CMIN: contrast media-induced nephropathy; SRMR: standardized root mean square residual, RMSEA root mean square error of approximation; GFI: goodness of fit index; AGFI: adjusted goodness of fit index; CFI: comparative fit index.

The results of confirmatory factor analysis are shown in Table 4. The standardized factor load of each question was more than 0.6 , the constituent reliability of each latent variable was more than 0.7 , and the average extraction amount of variation was more than 0.5 , all reaching the standard of convergence validity [61], indicating that the data had a good validity.

Table 4. The results of confirmatory factor analysis.

\begin{tabular}{|c|c|c|c|c|c|}
\hline & Questions & Standardized Factor Load & $p$ & CR & AVE \\
\hline \multirow{6}{*}{ Benefit perception } & A1 & 0.772 & & \multirow{6}{*}{0.919} & \multirow{6}{*}{0.656} \\
\hline & A2 & 0.809 & $* * *$ & & \\
\hline & A3 & 0.891 & $* * *$ & & \\
\hline & A4 & 0.734 & $* * *$ & & \\
\hline & A5 & 0.792 & $* * *$ & & \\
\hline & A6 & 0.851 & $* * *$ & & \\
\hline \multirow{5}{*}{ Cost perception } & B1 & 0.832 & & \multirow{5}{*}{0.885} & \multirow{5}{*}{0.607} \\
\hline & B2 & 0.733 & $* * *$ & & \\
\hline & B3 & 0.807 & $* * *$ & & \\
\hline & B4 & 0.697 & $* * *$ & & \\
\hline & B5 & 0.818 & $* * *$ & & \\
\hline \multirow{8}{*}{ Perceived justice } & $\mathrm{C} 1$ & 0.764 & & \multirow{8}{*}{0.898} & \multirow{8}{*}{0.528} \\
\hline & C2 & 0.794 & $* * *$ & & \\
\hline & C3 & 0.811 & $* * *$ & & \\
\hline & C4 & 0.808 & $* * *$ & & \\
\hline & C5 & 0.634 & $* * *$ & & \\
\hline & C6 & 0.699 & $* * *$ & & \\
\hline & C7 & 0.603 & $* * *$ & & \\
\hline & C8 & 0.666 & $* * *$ & & \\
\hline \multirow{5}{*}{ Community identity } & D1 & 0.832 & & \multirow{5}{*}{0.885} & \multirow{5}{*}{0.607} \\
\hline & D2 & 0.733 & $* * *$ & & \\
\hline & D3 & 0.807 & $* * *$ & & \\
\hline & D4 & 0.697 & $* * *$ & & \\
\hline & D5 & 0.818 & $* * *$ & & \\
\hline \multirow{6}{*}{$\begin{array}{c}\text { Support for tourism } \\
\text { development }\end{array}$} & E1 & 0.802 & & \multirow{6}{*}{0.916} & \multirow{6}{*}{0.645} \\
\hline & E2 & 0.818 & $* * *$ & & \\
\hline & E3 & 0.808 & $* * *$ & & \\
\hline & E4 & 0.795 & $* * *$ & & \\
\hline & E5 & 0.789 & $* * *$ & & \\
\hline & E6 & 0.808 & $* * *$ & & \\
\hline
\end{tabular}

Note: ${ }^{* * *} p<0.001$; C.R.: critical ratio; AVE: average variance extracted.

\subsection{Structural Equation Model Test}

The results for the SEM fitting degree had a value of $\mathrm{CMIN} / \mathrm{DF}=1.386$, SRMR $=0.072$, RMSEA $=0.034$, with incremental and absolute model fit indices (e.g., $\mathrm{GFI}=0.912$, AGFI $=0.893$, and $\mathrm{CFI}=0.977$ ). In the acceptable range (the standards are the same as Table 3), each fitting index met the general research standard [64]. Therefore, it could be considered that this model was well proportioned with a strong correlation.

Based on the confirmatory factor analysis, the latent variables and observed variables in the overall measurement model were introduced into the theoretical model to conduct 
SEM analysis, and the above research hypotheses were tested to obtain the path coefficient results of the theoretical model (Figure 4).

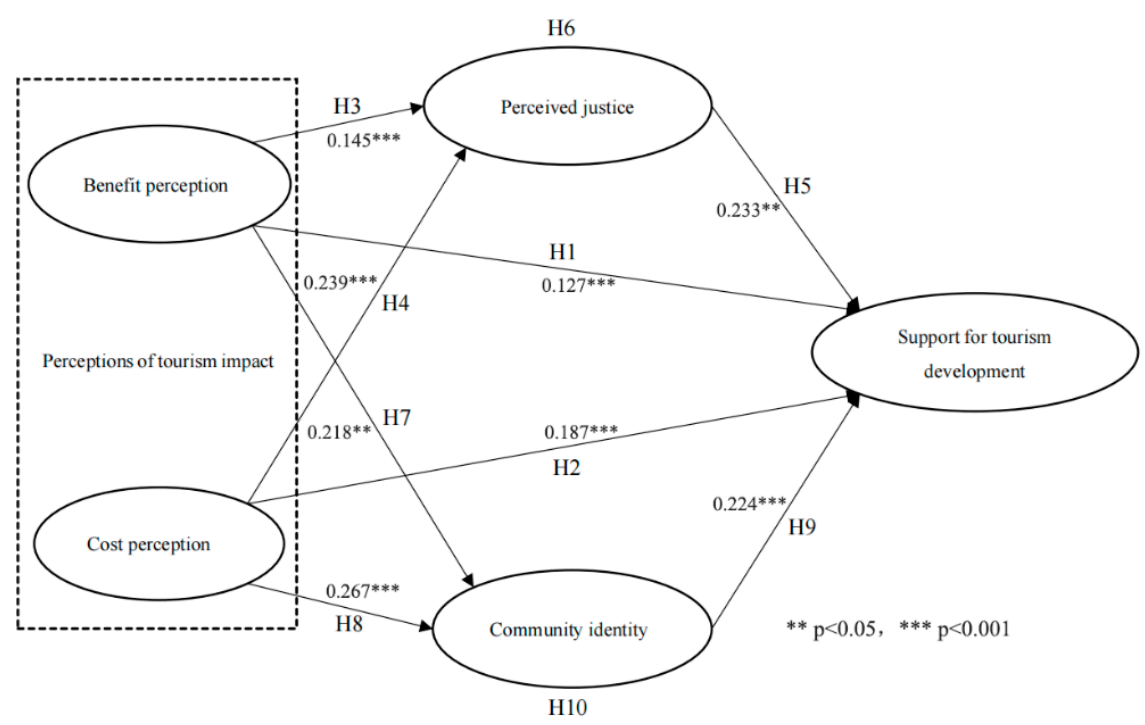

Figure 4. Results of structural equation modeling.

It can be seen from Figure 4 that benefit perception had a significantly positive influence on supporting tourism development $(\beta=0.127, p<0.001)$, and cost perception had a significantly negative influence on supporting tourism development $(\beta=0.187, p<0.001)$. Therefore, $\mathrm{H} 1$ and $\mathrm{H} 2$ were supported.

Benefit perception had a significantly positive influence on perceived justice $(\beta=0.145$, $p<0.001$ ), and cost perception had a statistically significant impact on perceived justice ( $\beta=0.239, p<0.001)$. Perceived justice had a significantly positive influence on supporting tourism development ( $\beta=0.233, p<0.05$ ). Therefore, $\mathrm{H} 3, \mathrm{H} 4$, and $\mathrm{H} 5$ were supported.

Benefit perception had a significantly positive influence on community identity ( $\beta=0.218, p<0.05)$, while cost perception had a significantly negative influence on community identity $(\beta=0.267, p<0.001)$. Community identity had a statistically significant impact on supporting tourism development $(\beta=0.224, p<0.001)$. Thus, H7, H8, and H9 were supported.

\subsection{Mediating Effect Test}

The repeated sampling was set at 2000 times, and the results are shown in Table 5. It is generally believed that when the confidence interval of the mediating effect does not contain 0, the corresponding direct, indirect, or total effect exists [65]. At a 95\% confidence level, the mediating effect test was conducted on perceived justice through the path 'tourism impacts perception, perceived justice and support for tourism development'. The confidence intervals of direct, indirect and total mediating effects of perceived justice were [0.511, 1.147], [0.055, 0.525] and [0.839, 1.255], respectively. It was established that perceived justice played an intermediary role in the relationship between tourism impact perception and support for tourism development and so H6 was supported. 
Table 5. Mediating effect test of perceived justice and community identity.

\begin{tabular}{ccc}
\hline \multicolumn{3}{c}{ Tourism's Impact $\rightarrow$ Perceived Justice $\rightarrow$ Support for Tourism Development } \\
\hline & Effects & $95 \%$ CI \\
Direct effects & 0.553 & {$[0.511,1.147]$} \\
Indirect effects & 0.254 & {$[0.055,0.525]$} \\
Total effects & 0.807 & {$[0.839,1.255]$} \\
Tourism's Impact $\rightarrow$ Community Justice $\rightarrow$ Support for Tourism Development \\
& Effects & $95 \%$ CI \\
Direct effects & 0.379 & {$[0.275,0.437]$} \\
Indirect effects & 0.152 & {$[0.053,0.098]$} \\
Total effects & 0.531 & {$[0.628,1.056]$} \\
\hline
\end{tabular}

Note: CI: Confidence Interval.

At a 95\% confidence level, the model also tested the mediating effect of community identity through the path 'tourism impacts perception, community identity and support for tourism development'. The confidence intervals of direct, indirect, and total intermediary effects of community identity were [0.275, 0.437], [0.053, 0.098] and [0.628, 1.056], respectively. It was suggested that community identity played an intermediary role in the relationship between tourism impact perception and support for tourism development, and $\mathrm{H} 10$ was supported.

\section{Discussion}

This research on the mechanism of the influence of local residents' perceptions of tourism's impact on supporting tourism in the GIAHS site of XHDA has revealed that perception has both direct and indirect influences on behavioral intentions. Firstly, the direct impact lies in the positive and negative attitudes in terms of the cost and benefit of tourism development. Residents' perceptions of the positive impacts of tourism were found to accurately predict their support for the development of CBT. This was similar to what was revealed elsewhere [36,39]. Meanwhile, perceived negative impacts were also found to weaken residents' support for tourism significantly, which was similar to the results found in some other studies [12].

In this GIAHS site, tourism development in the form of CBT received positive feedback from local residents. Tourism has generated employment opportunities and income for local residents. Local people directly provide transportation, accommodation, and catering services for tourists. They also benefit from the GIAHS branding system during the production, processing, and sales of agri-products, gaining added value. These income-generating opportunities in CBT development maximized the value of traditional livelihoods by branding them under the title of GIAHS while conserving the traditional system. These benefits were positively perceived by local residents to further enhance their support for and involvement in CBT to form the closed loop of CBT development. Therefore, CBT in XHDA has improved livelihood sustainability and improved the rural well-being of the community, making CBT a dynamic and adaptive management tool in GIAHS. From the perspective of cost impacts, residents were mostly sensitive to the expansion of the income gap. CBT has promoted the local tourism economy rapidly as a whole; however, its effects were not evenly distributed in each household because of the differences in the labor force and settlements' geographical distance from the core agri-landscape. This perception of the income gap intensified residents' perception of justice. In the process of CBT development in GIAHS, the significance of revenue for the regional financial budget is amplified since GIAHS managers tend to equate heritage sites with general tourist destinations, but other key elements of heritage conservation, such as psychological and cultural issues that community residents cared about, were often ignored.

The findings of this study strongly support the hypothesis that perceived justice and community identity have a significant mediating role between the perceptions of tourism impact and support for tourism development. This mediating role of emotions took effect 
on their behavioral intentions via its psychological transmission chain of perceptions. CBT responded to the demands of community residents for the rights to livelihood development, especially their participation and decision making in major community affairs related to tourism [66]. Thus, perceived justice and community identity positively responded to such rights demands by residents such that they took practical actions to promote or resist the development of CBT accordingly. In this psychological process, residents not only cared about the distribution justice of benefits; procedural and interactive justice were also important to them. Specifically, local residents were very concerned about whether the development of CBT respected their opinions and realized communication between all stakeholders in certain ways. At the same time, traditional rural customs were deeply rooted in the residents' perceptions of the GIAHS site, and community identity was closely attached to the local culture and institution. In this GIAHS site, Duotian was regarded as a precious source of heritage and wealth in the community and was the spiritual symbol of the community to a certain extent. This sense of responsibility and pride for community identity was often multiplied when negative perception was enhanced. Thus, the mediating role of perceived justice and community identity must be taken seriously for the development of CBT in GIAHS sites.

Residents' perceptions of benefit and cost were enhanced through the mediating role of perceived justice and community identity, and this can be explained by the particularity of GIAHS. Firstly, compared with other types of tourist attractions, the whole agri-system depends on the participation of residents to maintain its landscape and cultural values, which are embedded in the daily lives of residents. The agri-system and the residents complement each other and show a dynamic change in the process of system evolution. Different from traditional enclosed tourist attractions, GIAHS cannot be conservated as closed architectural heritage [67], which will only lead to the poverty of residents, the decline of GIAHS, and unsustainability for CBT. Secondly, the long history of GIAHS sites has formed a unique spiritual and cultural characteristic, i.e., community identity. Sometimes, cultural pride even exceeded economic value and thus affected the behavior of residents. In fact, community identity was revealed as an important factor because it reflected the different understanding of tourism development between GIAHS managers and residents. Residents regarded XHDA as a precious source of historical wealth for the local community, and the customs and traditions derived from XHDA have penetrated the life of every local household, becoming the soul of community identity [68]. The development of CBT not only represented the sustainability of livelihoods for local residents, but it was also regarded as a stage to show the long history and abundant culture of the local community. In this regard, this heartfelt pride and community identity represents a significant contradiction with the primary goal of profit-making with GIAHS managers. Therefore, traditional communities, their customs, and group characteristics formed over the centuries should be paid more attention to during the development of CBT in GIAHS sites.

\section{Conclusions}

In previous studies, scholars often formulated the research object in a traditional analytical form of an 'exchange of interests' [4]. However, there remained a lack of psychological cognition of residents. This study extends the literature by examining the mediating role of perceived justice and community identity between residents' perception of tourism's impact and their support for tourism development with the theories of SET and CAC. The findings of this study strongly support the proposed conceptual model and the hypotheses. Specifically, the findings suggest that perception had both direct and indirect influences on behavioral intentions. Tourism benefit perception had a significant positive influence, while tourism cost perception had a significant negative influence on supporting tourism development. The mediating roles of perceived justice and community identity were confirmed. Both of these factors played an important mediating role in residents' behavior. We argue that this analytical framework is better suited to understanding the complexities of the role of communities and residents in the GIAHS site. 
From the case of XHDA, the findings reveal that external benefit and cost perceptions were the primary factors affecting residents' support for tourism development, which were directly related to residents' basic livelihoods. In addition to these effects, perceived justice and community identity had significant mediating effects on residents' decisionmaking behaviors regarding CBT. Because this kind of research is still relatively rare in the GIAHS field, the analytical framework, with perceived justice and community identity as mediating variables, has theoretical and practical significance for GIAHS communities. In the management system of GIAHS sites, the traditional dual structure of 'external capital-tourism attractions' should be improved, and the participatory construction of the community should be emphasized in the management mode [25]. In terms of the benefit-sharing mechanism, the GIAHS site can try to establish a community development association (or group) to negotiate with external capital forces, so as to clarify the responsibility and benefit distribution of community residents in CBT. Moreover, the sense of procedural and interactional justice of residents should also be enhanced through standardized and transparent tourism decision-making and benefit distribution processes to avoid the imbalance of residents' perceived justice caused by the excessive income gap in CBT.

\section{Limitations and Future Directions}

This study has some limitations that need to be addressed by researchers. Firstly, as seen in previous studies and field investigations, there may be other key variables in the mechanism of the influence of local residents' perceptions of tourism's impact on supporting tourism. Future studies could consider in-depth interviews or focus groups to identify additional factors in this model and examine their role in this relationship. Secondly, considering the diversity of GIAHS types, trying to explore multiple cases to form a universal analytical framework is one of the research directions, contributing to the dynamic conservation and adaptive management of GIAHS sites. Furthermore, since this study was limited to local residents' perspectives, future studies could consider perspectives from immigrants or tourism enterprises to extend the results of this study.

Author Contributions: Conceptualization and methodology, B.W. and S.H.; investigation, data collection, and analysis, B.W., F.C. and G.W.; writing, reviewing and editing, B.W. and S.H.; supervision, Q.M. All authors have read and agreed to the published version of the manuscript.

Funding: This research was funded by 'Beautiful China' Ecological Civilization Construction Science and Technology Project (XDA23100203) and National Natural Science Foundation of China (42001194).

Institutional Review Board Statement: Not applicable.

Informed Consent Statement: Informed consent was obtained from all subjects involved in the study.

Data Availability Statement: The data presented in this study are available on request from the corresponding author. The data are not publicly available due to privacy or ethical restrictions.

Acknowledgments: The authors were grateful to the research interns from College of Humanities \& Social Development of Nanjing Agricultural University for their assistance in developing this research. The authors would like to thank all the anonymous interviewees who contributed their time and knowledge to this study.

Conflicts of Interest: The authors declare no conflict of interest.

\section{References}

1. World Tourism Organization. Tourism and Poverty Reduction; UNWTO: Madrid, Spain, 2002; pp. 1-115.

2. UNESCO. The effects of tourism on socio-cultural values. Ann. Tour. Res. 1976, 4, 74-105. [CrossRef]

3. Park, D.B.; Nunkoo, R.; Yoon, Y.S. Rural residents' attitudes to tourism and the moderating effects of social capital. Tour. Geogr. 2015, 17, 112-133. [CrossRef]

4. Sharpley, R. Host perceptions of tourism: A review of the research. Tour. Manag. 2014, 42, 37-49. [CrossRef]

5. Emerson, R.M. Social Exchange Theory. Annu. Rev. Sociol. 1976, 2, 335-362. [CrossRef]

6. Ap, J. Residents' perceptions on tourism impacts. Ann. Tour. Res. 1992, 19, 665-690. [CrossRef] 
7. Jurowski, C.; Uysal, M.; Williams, D.R. A Theoretical Analysis of Host Community Resident Reactions to Tourism. J. Travel Res. 1997, 36, 3-11. [CrossRef]

8. Andereck, K.L.; Valentine, K.M.; Knopf, R.C.; Vogt, C.A. Residents' perceptions of community tourism impacts. Ann. Tour. Res. 2005, 32, 1056-1076. [CrossRef]

9. Stylidis, D.; Biran, A.; Sit, J.; Szivas, E.M. Residents' support for tourism development: The role of residents' place image and perceived tourism impacts. Tour. Manag. 2014, 45, 260-274. [CrossRef]

10. Andereck, K.L.; Nyaupane, G.P. Exploring the Nature of Tourism and Quality of Life Perceptions among Residents. J. Travel Res. 2011, 50, 248-260. [CrossRef]

11. Ko, D.W.; Stewart, W.P. A structural equation model of residents' attitudes for tourism development. Tour. Manag. 2002, 23, 521-530. [CrossRef]

12. Diedrich, A.; Garcia-Buades, E. Local perceptions of tourism as indicators of destination decline. Tour. Manag. 2009, 30, 512-521. [CrossRef]

13. Nunkoo, R.; Smith, S.L.J. Political economy of tourism: Trust in government actors, political support, and their determinants. Tour. Manag. 2013, 36, 120-132. [CrossRef]

14. Latkova, P.; Vogt, C.A. Residents' Attitudes toward Existing and Future Tourism Development in Rural Communities. J. Travel Res. 2012, 51, 50-67. [CrossRef]

15. Baloglu, S. An Empirical Investigation of Attitude Theory for Tourist Destinations: A Comparison of Visitors and Nonvisitors. J. Hosp. Tour. Res. 1998, 22, 211-224. [CrossRef]

16. Li, P.; Yang, G. On the equity and efficiency of community participation in tourism development: Evidence from Yubeng Tibetan Village in Meili Snow Mountain, Yunnan. For. Econ. 2010, 42, 120-124. (In Chinese)

17. Shan, M. Research on the internal mechanism of the impact of tourism development on community cultural identity from the perspective of grounded theory. Dongyue Trib. 2015, 36, 132-137. (In Chinese)

18. Guo, A.; Wang, S.; Li, H.; Guo, Y. Influence mechanism of residents' perception of tourism impacts on supporting tourism development: Intermediary role of community satisfaction and community identity. Tour. Trib. 2020, 35, 96-108. (In Chinese)

19. He, S.; Su, Y.; Wang, L.; Cheng, H. Realisation of recreation in national parks: A perspective of ecosystem services demand and willingness to pay of tourists in Wuyishan Pilot. J. Nat. Resour. 2019, 34, 40-53. (In Chinese)

20. Min, Q.; He, L.; Sun, Y.; Zhang, D. On the value, conservation and sustainable development of GIAHS pilot sites in China. Chin. J. Eco-Agric. 2012, 20, 668-673. (In Chinese) [CrossRef]

21. Nkala, P.; Mango, N.; Zikhali, P. Conservation Agriculture and Livelihoods of Smallholder Farmers in Central Mozambique. J. Sustain. Agric. 2011, 35, 757-779. [CrossRef]

22. He, S.; Li, H.; Min, Q. Is GIAHS an Effective Instrument to Promote Agrosystem Conservation? A Rural Community's Perceptions. J. Resour. Ecol. 2020, 11,77-86.

23. Wang, B.; He, S.; Min, Q.; Cui, F. Framework for evaluating the development suitability of tourism resources in agricultural heritage systems: A case study of Qingyuan County in Zhejiang Province. Chin. J. Eco-Agric. 2020, 28, 1382-1396. (In Chinese)

24. Cui, F.; Wang, S.; Li, M. Study on the Relation Between Agro-Cultural Heritage Protection and Regional Economic, Social Development: Taking Xinghua's Duotian in Jiangsu Province as an Example. China Popul. Resour. Environ. 2013, $23,156-164$. (In Chinese)

25. Tang, X.; Yu, X.; Zhang, D. A study of agri-cultural heritage tourism impacts based on residents' perception: Taking the Longji terrace site in Guilin as an example. J. Resour. Ecol. 2013, 4, 267-274.

26. Xu, X.; Sun, F.; Wang, L. Effects of perceived justice on community participation in tourism development: From the perspective of community identification. China Popul. Resour. Environ. 2015, 25, 113-120. (In Chinese)

27. Rucker, D.D.; Preacher, K.J.; Tormala, Z.L.; Petty, R.E. Mediation analysis in social psychology: Current practices and new recommendations. Soc. Personal. Psychol. Compass 2011, 5, 359-371. [CrossRef]

28. Doxey, G.V. A Causation Theory of Visitor-Resident Irritants: Methodology and Research Inferences; Travel and tourism research associations: Lapeer, MI, USA, 1975; pp. 195-198.

29. Smith, V.L. Hosts and Guests: The Anthropology of Tourism; University of Pennsylvania Press: Philadelphia, PA, USA, 1989; pp. $1-352$.

30. Butler, R.W. The concept of a tourist area cycle of evolution: Implications for management of resources. Can. Geogr. 1980, 24, 5-12. [CrossRef]

31. Vargas-Sanchez, A.; Plaza-Mejia, M.D.; Porras-Bueno, N. Understanding Residents' Attitudes toward the Development of Industrial Tourism in a Former Mining Community. J. Travel Res. 2009, 47, 373-387. [CrossRef]

32. McGehee, N.G.; Andereck, K.L. Factors predicting rural residents' support of tourism. J. Travel Res. 2004, 43, 131-140. [CrossRef]

33. Zamani-Farahani, H.; Musa, G. The relationship between Islamic religiosity and residents' perceptions of socio-cultural impacts of tourism in Iran: Case studies of Sare'in and Masooleh. Tour. Manag. 2012, 33, 802-814. [CrossRef]

34. Gursoy, D.; Jurowski, C.; Uysal, M. Resident attitudes-A structural modeling approach. Ann. Tour. Res. 2002, 29, 79-105. [CrossRef]

35. Williams, J.; Lawson, R. Community issues and resident opinions of tourism. Ann. Tour. Res. 2001, 28, 269-290. [CrossRef]

36. Mason, P.; Cheyne, J. Residents' attitudes to proposed tourism development. Ann. Tour. Res. 2000, 27, 391-411. [CrossRef] 
37. Yoon, Y.; Gursoy, D.; Chen, J.S. Validating a tourism development theory with structural equation modeling. Tour. Manag. 2001, 22, 363-372. [CrossRef]

38. Madrigal, R. A tale of tourism in two cities. Ann. Tour. Res. 1993, 20, 336-353. [CrossRef]

39. Dyer, P.; Gursoy, D.; Sharma, B.; Carter, J. Structural modeling of resident perceptions of tourism and associated development on the Sunshine Coast, Australia. Tour. Manag. 2007, 28, 409-422. [CrossRef]

40. Snaith, T.; Haley, A. Residents' opinions of tourism development in the historic city of York, England. Tour. Manag. 1999, 20, 595-603. [CrossRef]

41. Lankford, S.V. Attitudes and perceptions toward tourism and rural regional development. J. Travel Res. 1994, 32, 35-43. [CrossRef]

42. Adams, J.S. Towards an understanding of inequity. J. Abnorm. Soc. Psychol. 1963, 67, 422. [CrossRef]

43. McQuilken, L.; McDonald, H.; Vocino, A. Is guarantee compensation enough? The important role of fix and employee effort in restoring justice. Int. J. Hosp. Manag. 2013, 33, 41-50. [CrossRef]

44. Bies, R.J.; Shapiro, D.L. Interactional fairness judgments: The influence of causal accounts. Soc. Justice Res. 1987, 1, 199-218. [CrossRef]

45. Smith, A.K.; Bolton, R.N.; Wagner, J. A model of customer satisfaction with service encounters involving failure and recovery. J. Mark. Res. 1999, 36, 356-372. [CrossRef]

46. Blodgett, J.G.; Hill, D.J.; Tax, S.S. The effects of distributive, procedural, and interactional justice on post complaint behavior. J. Retail. 1997, 73, 185-210. [CrossRef]

47. Murphy, P.E. Strategic Management for Tourism Communities: Bridging the Gaps; Channel View Publications: Bristol, UK, 2004; pp. 823-824.

48. Wahab, S.; Pigram, J. Tourism, Development and Growth: The Challenge of Sustainability; Psychology Press: London, UK, 1997; pp. 129-146.

49. Han, X.; Tian, T.; Sun, B. A “Perception-Identity-Engagement" model for the tourism virtual community. Tour. Trib. 2016, 31, 61-70. (In Chinese)

50. Proshansky, H.M.; Fabian, A.K.; Kaminoff, R. Place-identity: Physical world socialization of the self. J. Environ. Psychol. 1983, 3 , 57-83. [CrossRef]

51. De Bres, K.; Davis, J. Celebrating group and place identity: A case study of a new regional festival. Tour. Geogr. 2001, 3, 326-337. [CrossRef]

52. Carrus, G.; Bonaiuto, M.; Bonnes, M. Environmental concern, regional identity, and support for protected areas in Italy. Environ Behav. 2005, 37, 237-257. [CrossRef]

53. Food and Agriculture Organization of the United Nations. GIAHS Proposal: Xinghua Duotian Agrosystem, China; FAO: Rome, Italy, 2014; pp. 1-66.

54. Eslami, S.; Khalifah, Z.; Mardani, A.; Streimikiene, D.; Han, H. Community attachment, tourism impacts, quality of life and residents' support for sustainable tourism development. J. Travel Tour. Mark. 2019, 36, 1061-1079. [CrossRef]

55. Stylidis, D. Place Attachment, Perception of Place and Residents' Support for Tourism Development. Tour. Plan. Dev. 2018, 15, 188-210. [CrossRef]

56. Nawijn, J.; Mitas, O. Resident Attitudes to Tourism and Their Effect on Subjective Well-Being. J. Travel Res. 2012, 51, 531-541. [CrossRef]

57. Cheng, K. Characteristics and application of structural equation model. Stat. Decis. 2006, 22, 22-25. (In Chinese)

58. Henseler, J.; Ringle, C.M.; Sarstedt, M. A new criterion for assessing discriminant validity in variance-based structural equation modeling. J. Acad. Mark. Sci. 2015, 43, 115-135. [CrossRef]

59. Rasoolimanesh, S.M.; Ringle, C.M.; Jaafar, M.; Ramayah, T. Urban vs. rural destinations: Residents' perceptions, community participation and support for tourism development. Tour. Manag. 2017, 60, 147-158. [CrossRef]

60. Fang, J.; Zhang, M. Assessing point and interval estimation for the mediating effect: Distribution of the product, nonparametric bootstrap and Markov Chain Monte Carlo methods. Acta Psychol. Sin. 2012, 44, 1408-1420. (In Chinese) [CrossRef]

61. Li, C.; Xin, L. Research on the evaluation method of reliability and validity of questionnaire. Chin. J. Health Stat. 2008, 25, 541-544. (In Chinese)

62. Fu, D. Statistical test in principal component analysis. Stat. Educ. 2007, 14, 4-7. (In Chinese)

63. Li, Y.; Huang, Z. The role of confirmatory factor analysis in the structural validity of the scale. Chin. J. Public Health 2007, 23, 1198-1199. (In Chinese)

64. Fang, P.; Xiong, D.; Cao, X. The development and application of structural equation model. Adv. Psychol. Sci. 2002, 10, 270-279. (In Chinese)

65. Zhang, H.; Kang, F. Analysis of multiple mediating effects based on bootstrap. Stat. Decis. 2016, 23, 75-78. (In Chinese)

66. Curcija, M.; Breakey, N.; Driml, S. Development of a conflict management model as a tool for improved project outcomes in community-based tourism. Tour. Manag. 2019, 70, 341-354. [CrossRef]

67. Sun, Y.; Min, Q.; Cheng, S.; Zhong, L. Study on the tourism resource characteristics of agricultural heritage. Tour. Trib. 2010, 25, 57-62. (In Chinese)

68. Ruiz Ballesteros, E.; Hernández Ramírez, M. Identity and community-Reflections on the development of mining heritage tourism in Southern Spain. Tour. Manag. 2007, 28, 677-687. [CrossRef] 